\title{
Twinning rate trend in a population sample from the city of São Paulo, Brazil
}

\author{
Gloria M.D.D. Colletto \\ Universidade de São Paulo, Instituto de Ciências Biomédicas, Departamento de Parasitologia, \\ São Paulo, SP, Brazil.
}

\begin{abstract}
A retrospective study was carried out on a sample consisting of 89,491 deliveries occurred from 1979 through 1998 , in the city of São Paulo, SP, Brazil. These deliveries included 935 twin and 26 triplet births. The mean incidence per 1,000 deliveries was estimated at 10.45 for twins (5.34 for dizygotic and 5.11 for monozygotic twins) and 0.29 for triplets. The average maternal age increased significantly during this period for both twins and singletons. The temporal variation in years significantly influenced the increase of monozygotic twins and of triplets. Temporal variation and maternal age significantly influenced the dizygotic twinning rate increase. An increased proportion of monozygotic twins born to mothers aged 31 - 35 years was also detected.
\end{abstract}

Key words: Dizygotic twinning rate, monozygotic twinning rate, maternal age, gestational order, gestational age.

Received: August 7, 2002; Accepted: May 21, 2003.

\section{Introduction}

The dizygotic twinning rate is positively correlated with maternal age and parity (Allen and Parisi, 1990; Beiguelman et al., 1996), as well as with assisted reproduction (Keith et al., 2000; Kiely and Kiely, 2001; Colletto et al., 2001). Prior to the widespread use of assisted reproduction techniques, a decrease in the dizygotic twinning rate had been observed in most of the urban populations studied (Beiguelman et al., 1996). The dizygotic twinning rate has remained unchanged, but lately some authors have observed a small increase in the frequency of monozygotic twin births (Bressers et al., 1987; Allen and Parisi, 1990; Beiguelman et al., 1996). This rise might be the consequence of residual effects of the long-term use of oral contraceptives, since they promote tubal motility depression and changes in the endometrial mucosa and in the oviduct epithelium (Bressers et al., 1987; Beiguelman et al., 1996).

This work aimed at estimating the variation in the incidence of multiple births in a sample of mothers belonging preferentially to the upper and middle socioeconomic classes, and the effects of non-genetic variables, such as the increase of maternal age, on the twinning rate.

\section{Subjects and Methods}

A retrospective study was carried out to investigate the twinning rate from 1979 through 1998 at Hospital Santa

Send correspondence to Gloria M.D.D. Colletto. Universidade de São Paulo, Av. Prof. Lineu Prestes 1730, ICB4, 05508-900 São Paulo, SP, Brazil. E-mail: gloriadc@usp.br.
Catarina, in the city of São Paulo, Brazil. The population seeking medical attention at this hospital belongs to the upper and middle socioeconomic layers. During this period, 89,491 deliveries took place, 88,530 of them of singletons, 935 of twins, and 26 of triplets. These figures include stillbirths, except for fetuses weighing $500 \mathrm{~g}$ or less at birth which were excluded, since this weight range corresponds to a gestational age between 20 and 22 weeks, and therefore they were considered as abortions. All data were obtained from hospital records. The whole set of data was used to estimate the frequency of twin and triplet births in relation to the total annual deliveries. To compare the maternal age and gestational order of singletons and twins, all multiple births and five to six singleton births per month were considered, totaling 1,400 singletons. Zygosity tests were not performed, and the frequency of dizygotic (DZ) pairs was estimated by Weinberg's method. A stepwise multiple regression analysis model was used to study the influence of maternal age, gestational order, and temporal variation on multiple births. The independent variables were: maternal age, squared maternal age, gestational order, squared gestational order, maternal age times gestational order, temporal variation, and squared temporal variation. The comparison of maternal age and gestational order was performed using Kruskal-Wallis's non-parametric test $\left(\chi^{2}\right)$, followed by Dunn's multiple comparison test (Q). Spearman's correlation coefficient was used to verify the association of monozygotic twin birth with maternal age. The commercial software SPSS version 9.0 was used for the statistical analyses. 


\section{Results}

During the 20-year period (1979-1998) covered by this study, the average frequency of twins per thousand deliveries was 10.45, being 5.34 for DZ (dizygotic) and 5.11 for MZ (monozygotic). The estimated triplet rate was $0.29 \%$ (Table 1). Stepwise multiple regression analysis revealed that temporal and squared temporal variations had a significant influence on the MZ birth rate $[\mathrm{MZR}=3.693+$ $0.0806 \times$ temporal variation $+0.0036 \times$ (temporal variation $)^{2}$ ], while the DZ rate was significantly influenced not only by temporal and squared temporal variations, but also by maternal age and squared maternal age $[\mathrm{DZR}=7.884+$ $0.229 \times$ (temporal variation $)^{2}-0.371 \times$ temporal variation + $0.0029 \times$ (maternal age $)^{2}-0.148 \times$ maternal age $]$. Only the temporal variation had a significant influence $[$ TriR $=-0.485+0.0829 \times$ temporal variation $]$ on the triplet birth rate (Figure 1).

The maternal ages for singletons, twins and triplets were shown to differ statistically (Table 2). The maternal age for twins was significantly higher than that for singletons $(\mathrm{Q}=3.57 ; \mathrm{p}<0.005)$, but the ages of mothers of triplets did not differ from those of singletons and twins $(\mathrm{Q}=0.88 ; \mathrm{p}>0.50$ and $\mathrm{Q}=0.11 ; \mathrm{p}>0.50$, respectively).
Over this 20-year period, the mean maternal age increased significantly for both singletons and twins, as shown by regression analysis. Temporal variation influenced significantly both singleton and twin birth rates $(\mathrm{F}=43.65 ; \mathrm{p}<0.001$ and $\mathrm{F}=41.66 ; \mathrm{p}<0.001$, respectively). Although the mean age of mothers of twins was

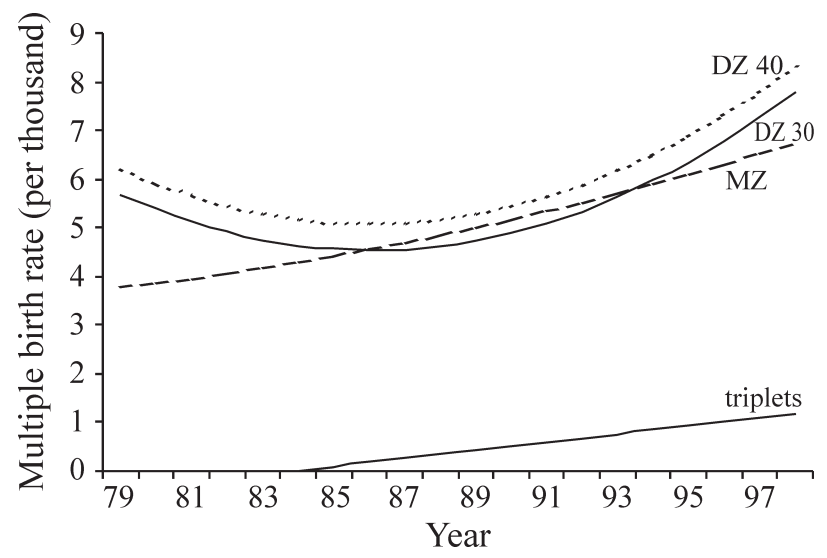

Figure 1 - Best-fit regression curves for the annual distribution rates of monozygotic (MZ) and dizygotic (DZ) twins, and triplets. As dizygotic twin rates are dependent on temporal variation (years) and on maternal age, two curves are shown, for mothers aged 30 (DZ-30) and 40 years (DZ-40).

Table 1 - Number of singleton, twin and triplet births from 1979 to 1998. $(\mathrm{MM}=$ male/male, $\mathrm{FF}=$ female/female, $\mathrm{MF}=$ male/female; rates per thousand: $\mathrm{DZR}=$ dizygotic twins, $\mathrm{MZR}=$ monozygotic twins, $\mathrm{TR}=$ total twins and TriR $=$ triplets .

\begin{tabular}{|c|c|c|c|c|c|c|c|c|c|c|}
\hline \multirow[b]{2}{*}{ Year } & \multicolumn{6}{|c|}{ Number of deliveries } & \multicolumn{4}{|c|}{ Rates per thousands } \\
\hline & Singleton & Twins & MM & $\mathrm{FF}$ & MF & Triplets & DZR & MZR & TR & TriR \\
\hline 1979 & 775 & 9 & 5 & 1 & 3 & 0 & 7.65 & 3.83 & 11.48 & 0.00 \\
\hline 1980 & 1692 & 15 & 8 & 3 & 4 & 0 & 4.69 & 4.10 & 8.79 & 0.00 \\
\hline 1981 & 2355 & 16 & 7 & 3 & 6 & 0 & 5.06 & 1.69 & 6.75 & 0.00 \\
\hline 1982 & 3150 & 30 & 12 & 10 & 8 & 0 & 5.03 & 4.40 & 9.43 & 0.00 \\
\hline 1983 & 3862 & 43 & 21 & 13 & 9 & 1 & 4.61 & 6.40 & 11.01 & 0.26 \\
\hline 1984 & 3969 & 29 & 4 & 14 & 11 & 0 & 5.50 & 1.75 & 7.25 & 0.00 \\
\hline 1985 & 4892 & 40 & 22 & 8 & 10 & 0 & 4.06 & 4.06 & 8.11 & 0.00 \\
\hline 1986 & 5789 & 52 & 20 & 19 & 13 & 1 & 4.45 & 4.45 & 8.90 & 0.17 \\
\hline 1987 & 5464 & 51 & 28 & 14 & 9 & 0 & 3.26 & 5.98 & 9.25 & 0.00 \\
\hline 1988 & 6069 & 54 & 25 & 16 & 13 & 1 & 4.25 & 4.57 & 8.82 & 0.16 \\
\hline 1989 & 6818 & 74 & 20 & 32 & 22 & 2 & 6.38 & 4.35 & 10.74 & 0.29 \\
\hline 1990 & 6332 & 68 & 29 & 23 & 16 & 1 & 5.00 & 5.63 & 10.63 & 0.16 \\
\hline 1991 & 5745 & 55 & 20 & 22 & 13 & 1 & 4.48 & 5.00 & 9.48 & 0.17 \\
\hline 1992 & 4784 & 49 & 20 & 19 & 10 & 2 & 4.14 & 6.00 & 10.14 & 0.41 \\
\hline 1993 & 4673 & 62 & 20 & 22 & 20 & 1 & 8.45 & 4.65 & 13.09 & 0.21 \\
\hline 1994 & 4694 & 50 & 14 & 24 & 12 & 1 & 5.06 & 5.48 & 10.54 & 0.21 \\
\hline 1995 & 4740 & 66 & 27 & 25 & 14 & 8 & 5.83 & 7.91 & 13.73 & 1.66 \\
\hline 1996 & 5028 & 58 & 27 & 17 & 14 & 2 & 5.51 & 5.90 & 11.40 & 0.39 \\
\hline 1997 & 4413 & 69 & 27 & 22 & 20 & 3 & 8.92 & 6.47 & 15.38 & 0.67 \\
\hline 1998 & 3286 & 45 & 16 & 17 & 12 & 2 & 7.20 & 6.30 & 13.51 & 0.60 \\
\hline Total & 88530 & 935 & 372 & 324 & 239 & 26 & 5.34 & 5.11 & 10.45 & 0.29 \\
\hline
\end{tabular}


Table 2 - Maternal age means and standard deviations (SD), and gestational order for singletons, twins and triplets.

\begin{tabular}{llrrrrrr}
\hline & Deliveries & Number & Mean & SD & Mean rank & $\chi^{2}$ & P \\
\hline \multirow{3}{*}{$\begin{array}{l}\text { Maternal } \\
\text { age }\end{array}$} & Singletons & 1400 & 28.79 & 4.82 & 1134.7 & & \\
& Twins & 926 & 29.57 & 4.90 & 1237.1 & 13.14 & 0.001 \\
& Triplets & 26 & 29.42 & 5.16 & 1252.6 & & \\
\multirow{3}{*}{$\begin{array}{l}\text { Gestational } \\
\text { order }\end{array}$} & Singletons & 1400 & 1.90 & 1.02 & 1173.0 & & \\
& Twins & 926 & 1.96 & 1.08 & 1204.0 & 7.46 & 0.024 \\
\hline
\end{tabular}

higher than that of mothers of singletons, the slopes of the two regression lines did not differ significantly. The mean age of mothers of singletons changed from $27.73 \pm 4.51$ to $30.41 \pm 4.99$, while the age of mothers of twins increased from $28.13 \pm 4.49$ to $31.22 \pm 5.58$ years.

The gestational order differed among the three groups (Table 2), but a multiple comparison test showed that singletons did not differ from twins $(\mathrm{Q}=1.07$; $\mathrm{p}>0.50)$ or from triplets $(\mathrm{Q}=2.22 ; 0.10>\mathrm{p}>0.05)$; the gestational order of triplets, however, was lower than that of twins $(\mathrm{Q}=2.44 ; \mathrm{p}<0.05)$. Regression analysis showed a decreasing trend in the gestational order of twins, beginning in the 1990s.

Considering six maternal age groups $(\leq 20,21-25$, $26-30,31-35,36-40, \geq 41$ ), a negative correlation was observed between maternal age and the proportion of monozygotic twins among twin births of each group (93.1\% in the age group $\leq 20$, and $40.0 \%$ in the age group $\geq 41$; $\left.r_{\mathrm{s}}=-0.829 ; \mathrm{p}=0.042\right)$. When the two groups of mothers that comprise $65.9 \%$ of the total of twin births (25-30 and 31-35 years old) were analyzed with regard to gestational order, the proportion of monozygotic twins showed an unexpected distribution: up to the gestational order 3, the proportion was approximately constant in both groups; however, for gestational orders 4 or higher, the proportion of monozygotic twins increased among twins born to mothers 31-35 years old (Figure 2).

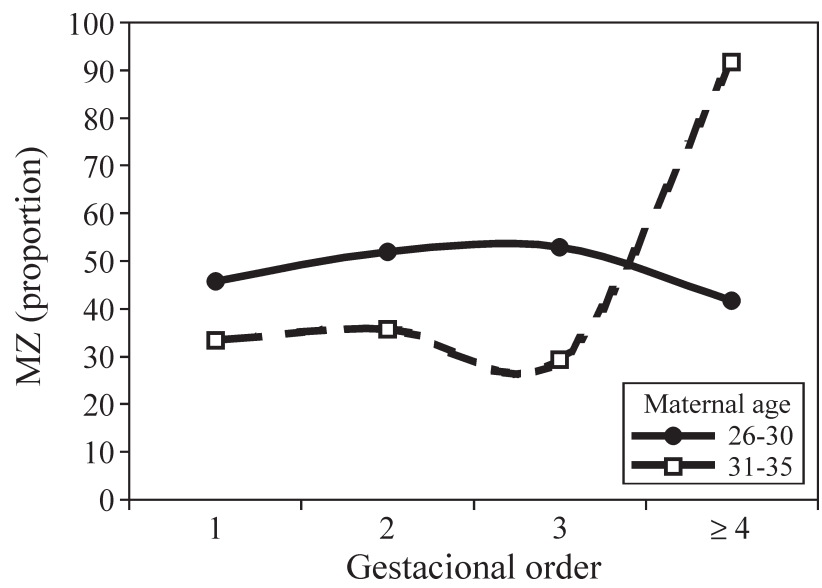

Figure 2 - Monozygotic twin proportions in two maternal age groups (26-30 and 31-35 years) according to gestational order.
The gestational ages in weeks varied significantly $\left(\chi^{2}=195.13 ;\right.$ d.f. $\left.=2 ; \mathrm{p}<0.001\right)$ among singletons $(39.06 \pm 1.48)$, twins $(36.90 \pm 2.76), \quad$ and triplets $(30.37 \pm 7.31)$. Low birth weight was found in $51.2 \%$ of twins and $88.2 \%$ of triplets.

\section{Discussion}

It is well established that maternal age is positively correlated with the dizygotic twin rate, but not with monozygotic twinning (Beiguelman et al., 1996; SteegersTheunissen et al., 1998; Keith et al., 2000). Among people of the middle and upper socioeconomic classes, the access to assisted reproduction techniques is growing, and this is correlated with multiple pregnancies (Steegers-Theunissen et al., 1998; Keith et al., 2000; Colletto et al., 2001). So, we cannot discard the possibility of this fact contributing to the rise of the incidence of dizygotic twin and triplet births.

Gestational order has been previously shown to be positively correlated with the incidence of twinning (Allen and Parisi, 1990), but this was not found in this survey. Assisted reproduction techniques used in primigravidae in recent years may be the cause of the decrease of the mean gestational order of twins and triplets that we observed.

Previous studies have shown a decrease in the proportion of $\mathrm{MZ}$ pairs among twins as maternal age increases (Beiguelman et al., 1995), a finding corroborated by this study. Thus, the incidence of MZ twins in our sample should be expected to decline over time, due to the increased maternal age. The opposite, in fact, occurred, since the proportion of MZ pairs has increased during the 20-year period. This could be the consequence of long-term use of oral contraceptives with residual effects on the subdivision of the segmented zygote (Pinkerton and Carey, 1976; Bressers et al., 1987). Mothers aged 31 to 35 years with a gestational order equal to or higher than four (Figure 2), could have been on oral contraceptives longer than the younger ones.

\section{Acknowledgments}

I am extremely grateful to Dr. Bernardo Beiguelman for his suggestions and collaboration, and to Mrs. Maria Norma A. de Claure who allowed the access to the data records of Hospital Santa Catarina. This research was sup- 
ported by Fundação de Amparo à Pesquisa do Estado de São Paulo (FAPESP) and Conselho Nacional de Desenvolvimento Científico e Tecnológico (CNPq).

\section{References}

ACOG educational bulletin (1999). Special problems of multiple gestations. Number 253, November 1998 (Replaces Number 131, August 1989). American College of Obstetricians and Gynecologists. Int J Gynaecol Obstet 64:323-333.

Allen G and Parisi P (1990) Trends in monozygotic and dizygotic twinning rates by maternal age and parity. Further analysis of Italian data, 1949-1985, and rediscussion of US data, 1964-1985. Acta Genet Med Gemellol 39:317-328.

Beiguelman B, Franchi-Pinto C, Colletto GMDD and Krieger H (1995) Annual variation of sex ratio in twin births and in singletons in Brazil. Acta Genet Med Gemellol 44:163-168.

Beiguelman B, Franchi-Pinto C, Krieger H and Magna LA (1996) Twinning rate in a Southwestern Brazilian population. Acta Genet Med Gemellol 45:317-324.
Bressers WM, Eriksson AW, Kostense PJ and Parisi P (1987) Increasing trend in the monozygotic twinning rate. Acta Genet Med Gemellol 36:397-408.

Colletto GMDD, Segre CAM and Beiguelman B (2001) Twinning rate in a Southeastern Brazilian population with a high standard of reproductive care. São Paulo Med J 119:216-219.

Keith LG, Oleszczuk JJ and Keith DM (2000) Multiple gestation: Reflections on epidemiology, causes and consequences. Int J Fertil Womens Med 45:206-214.

Kiely JL and Kiely M (2001) Epidemiological trends in multiple births in the United States, 1971-1998. Twin Res 4:131-133.

Pinkerton GD and Carey HM (1976) Post-pill anovulation. Med J Aust 1:220-222.

Steegers-Theunissen RP, Zwertbroek WM, Huisjes AJM, Kanhai HH, Bruinse HW and Merkus HM (1998) Multiple birth prevalence in The Netherlands. Impact of maternal age and assisted reproductive techniques. J Reprod Med 43:173-179.

Tong S and Short RV (1998) Dizygotic twinning as a measure of human fertility. Hum Reprod 13:95-98. 